\title{
BMJ Open Use of a service evaluation and lean thinking transformation to redesign an NHS 111 refer to community Pharmacy for Emergency Repeat Medication Supply Service (PERMSS)
}

\author{
Hamde Nazar, ${ }^{1}$ Zachariah Nazar, ${ }^{2}$ Jill Simpson, ${ }^{3}$ Andre Yeung, ${ }^{4}$ Cate Whittlesea ${ }^{1}$
}

To cite: Nazar H, Nazar Z, Simpson J, et al. Use of a service evaluation and lean thinking transformation to redesign an NHS 111 refer to community Pharmacy for Emergency Repeat Medication Supply Service (PERMSS). BMJ Open 2016;6:e011269. doi:10.1136/bmjopen-2016011269

- Prepublication history and additional material is available. To view please visit the journal (http://dx.doi.org/ 10.1136/bmjopen-2016011269).

Received 23 January 2016 Revised 10 June 2016 Accepted 14 July 2016

\footnotetext{
${ }^{1}$ School of Medicine, Pharmacy and Health, Durham University, StocktonOn-Tees, UK

${ }^{2}$ School of Pharmacy and Biomedical Sciences, University of Portsmouth, Portsmouth, UK ${ }^{3}$ Department of Clinical Strategy, NHS England North Cumbria and the North East, Durham, UK

${ }^{4}$ Newcastle City Council, Newcastle upon Tyne, UK
}

Correspondence to Dr Hamde Nazar; hamde.nazar@durham.ac.uk

\section{ABSTRACT}

Objectives: To demonstrate the contribution of community pharmacy from NHS 111 referrals out of hours $(\mathrm{OOH})$ for emergency supply repeat medication requests via presentation of service activity, community pharmacist feedback and lean thinking transformation. Design: Descriptive service evaluation using routine service activity data over the pilot period; survey of community pharmacists, and service redesign through lean thinking transformation.

Setting: North East of England NHS 111 provider and accredited community pharmacies across the North East of England.

Participants: Patients calling the North East of England NHS 111 provider during $\mathrm{OOH}$ with emergency repeat medication supply requests.

Interventions: NHS 111 referral to community pharmacies for assessment and if appropriate, supply of emergency repeat medication.

Main outcome measures: Number of emergency repeat medication supply referrals, completion rates, reasons for rejections, time of request, reason for access, medication(s), pharmaceutical advice and services provided. Secondary outcomes were community pharmacist feedback and lean thinking transformation of the patient pathway.

Results: NHS 111 referred 1468 patients to 114 community pharmacies (15/12/2014-7/4/2015). Most patients presented on Saturdays, with increased activity over national holidays. Community pharmacists completed 951 (64.8\%) referrals providing 2297 medications; 412 were high risk. The most common reason for rejecting referrals was no medication in stock. Community pharmacists were positive about the provision of this service. The lean thinking transformation reduced the number of non-added value steps, waits and bottlenecks in the patient pathway.

Conclusions: NHS 111 can redirect callers $00 \mathrm{H}$ from urgent and emergency care services to community pharmacy for management of emergency repeat medication supply. Existing IT and community pharmacy regulations allowed patients to receive a medication supply and pharmaceutical advice.

\section{Strengths and limitations of this study}

- The study reports on the routine service data collection carried out during the service implementation and delivery.

- This study demonstrates best practice to service designers and developers in employing NHS guidance on lean thinking transformation when evaluating and developing services to improve efficiency and effectiveness of services.

- A process evaluation is required to fully investigate and understand the true value of this service within the wider NHS.

- Patient perspectives of this service should be collected to evaluate the impact on the acceptability, and access and quality of care.

Community pharmacists supported integration into the $\mathrm{NHS} \mathrm{OOH}$ services. Adopting lean thinking provided a structured framework to evaluate and redesign the service with the aim to improve effectiveness and efficiency.

\section{INTRODUCTION}

NHS 111 was established as the new public telephonic access route to the NHS in Easter 2013. It replaced NHS Direct and differed in key areas such as a reduction in clinical input in assessments; did not aim to promote self-care; met a narrower range of patient needs and used clinical content that was new to the urgent care setting. ${ }^{1}$

The NHS Pathways system is the computerised decision support software (CDSS) used by NHS 111 non-clinical call handlers to assess all in-coming calls. This platform incorporates a Directory of Services (DoS), which is a single source of information that identifies local services. ${ }^{2}$ It has been suggested that the software responds well to 
emergency cases such as chest pain or breathing difficulties but appears less able to support call handlers to signpost callers to an appropriate level of non-urgent care. As a result, callers are directed to other face-to-face NHS services listed within the DoS rather than provided with support to care for themselves. ${ }^{1}$ The evaluation of the NHS 111 pilot sites demonstrated that only $8 \%$ of patients using the service were given advice to look after themselves without the need for onward referral. This CDSS has also been determined as more risk averse than the previous CDSS used by NHS Direct and was not intended for use in an urgent care setting. ${ }^{1}$

The evaluation of the NHS 111 pilot services was unable to define the likely impact of NHS 111 on the wider NHS urgent and emergency care system. ${ }^{3}$ However, early data following the national launch suggested that urgent and emergency care services were being adversely affected by the increased demand. ${ }^{1}$

A high demand on the urgent and emergency care services out of normal opening hours (evenings, weekends and holiday periods) with record numbers of calls made to NHS 111 during December 2014 was identified. ${ }^{4}$ One factor contributing to this workload was callers' requests for missed or lost repeat medication that comprised $15 \%$ of calls at busy times, for example, out of normal opening hours, bank holidays and weekends. ${ }^{6}$

Community pharmacists are legally permitted under the Human Medicines Regulations to provide emergency supplies of prescription-only medicines (POMs) at the request of the patient without a prescription. The legislation requires that pharmacists clinically assess patient need and act according to their professional judgement. ${ }^{7}$ Community pharmacy is a highly accessible point of healthcare for the public, as $\sim 90 \%$ of the population can access a community pharmacy within a 20 min walk and no appointment is required. ${ }^{8}$ In addition, awareness of the potential contribution of pharmacists to urgent and emergency care has increased. The NHS Five Year Forward View stressed the need to make greater use of pharmacists. ${ }^{9}$ The Royal Pharmaceutical Society (RPS), the professional representative body for pharmacy, policy document, 'Shaping pharmacy for the future: improving urgent and emergency care through better use of pharmacists' recommended that the national contract by NHS England for community pharmacists should provide a common ailment service; a pharmacist should be incorporated into Accident and Emergency departments to manage medication-related issues and that pharmacists are a referral option within NHS 111 to support urgent and emergency care, particularly for common ailments and emergency supplies of medicines. ${ }^{10}$

In November 2014, an NHS Community Pharmacy Emergency Repeat Medication Supply Service (PERMSS) was commissioned by NHS England North, as a pilot working across Cumbria and the North East, and supported by local clinical commissioning groups
(CCGs), running from 15 December 2014 to 7 April 2015. The service proposal was produced by a project team consisting of members from the Local Pharmacy Network (LPN), Commissioning Support Unit 111 Directory of Service and NHS England. The purpose of this scheme was to enable patients calling NHS 111 out of hours $(\mathrm{OOH})$ with requests for repeat medication emergency supplies to be directed to an open community pharmacy where they could obtain an emergency medication supply before their next dose. NHS 111 followed standard procedures entering patient details into the NHS Pathways CDSS but also used an information technology (IT) referral platform, PharmOutcomes, a web-based system collating information and facilitating management of local service provision. ${ }^{11}$ The service specification ${ }^{12}$ was circulated to all community pharmacies $(n=711)$ across the North East. An information sheet of frequently asked questions was disseminated to all confirmed, eligible community pharmacy providers. A short period of testing preceded service launch.

\section{SERVICE INTERVENTION FOR NHS 111 REFERRED PATIENTS}

The service intervention was designed so that patients making a call to NHS $111 \mathrm{OOH}$ talked with a call handler who used the CDSS standardised format of questioning to arrive at an appropriate recommendation for the patient. The specified $\mathrm{OOH}$ times during this evaluative period was defined as Monday to Friday between 18:30 and 08:00, weekends (Friday to Monday between 18:30 and 08:00), Christmas Eve and New year's eve between 18:00 and 08:00 and at any time on specified days (Christmas day, Boxing day, New Year's day, Easter Friday and Easter Monday). NHS Pathways was adapted so that emergency supply requests for repeat medications would alert the call handler to refer the patient to a community pharmacy rather than the default General Practitioner (GP) OOH option. The DoS provided the contact details of the nearest community pharmacies open at the time and accredited to provide PERMSS allowing the patient to select and choose where the referral should be sent. Call handlers then duplicated the patient personal details and missing medications onto PharmOutcomes. At the end of the call, this was then automatically sent to the selected community pharmacy. Patients were advised to visit that community pharmacy with evidence of their repeat medication, for example, a repeat prescription request form, a recently dispensed, labelled empty box of medication, a recent GP letter or any other evidence that demonstrated the medication was regularly prescribed. Community pharmacists could then check PharmOutcomes to retrieve the referral and contact the patients using the details provided to clinically assess their need for a supply. In some cases, patients could present at the community pharmacy before the community pharmacist had checked PharmOutcomes, at which point the 
community pharmacist would access the referral and carry out the clinical assessment for medication supply. This was followed by one of three outcomes:

- An emergency supply was made, in accordance with the Human Regulations $2012^{7}$ as no further clinical advice was required and the POM was available in the community pharmacy;

- The patient was advised to try another pharmacy because, although no further clinical advice was required, the POM was unavailable at the community pharmacy;

- The patient was advised to contact another appropriate healthcare service, for example, NHS 111 or a walk-in centre because further clinical advice was needed.

When an emergency supply was made, the community pharmacist provided up to seven days' supply, except where it was not possible to dispense such volumes, for example, inhaler, creams. In such cases, the smallest pack size was dispensed. The regulations also prevent emergency supply of Schedule 1, 2 or 3 controlled drugs with the exception of phenobarbitone or phenobarbitone sodium for epilepsy. ${ }^{7}$ Patients who were exempt for prescription payment received the medications free of charge, while those not exempt paid the standard prescription charge (£8.20). A professional fee linked to the number of items supplied (£10+£2 for each additional item) together with reimbursement of the cost of the medicine (Drug Tariff prices plus VAT) was paid for each emergency supply.

The supply was recorded in accordance with the usual procedure within each community pharmacy. A record of this supply was also made in PharmOutcomes, detailing patient name, address, verbal consent for supply, medication(s) supplied, nature of emergency, evidence provided and if further pharmaceutical advice or service was needed. A copy of the record was sent to the patient's GP using the PharmOutcomes email notification facility. This included any relevant concerns, advisory notes or issues identified. Further patient pharmaceutical advice could have consisted of effective medicines management, prescription request process and/or medicines reconciliation. Additional services that could also have been provided were a Medicines Use Review (MUR) or consent obtained for repeat dispensing.

Community pharmacists were then required to disclose the final result of the referral on PharmOutcomes as outlined below:

- Accepted: the referral was acknowledged and the community pharmacist followed-up by contacting the patient;

- Completed: the referral was acknowledged, actioned and resulted in an emergency supply medication being issued to the patient;

- Rejected: the referral was acknowledged and rejected. An open box was provided for community pharmacists to record reasons for rejection.
If a community pharmacist had not acknowledged the referral in PharmOutcomes nor registered any action taken, then the status of that referral remained recorded as 'referred' on the system.

\section{LEAN THINKING TRANSFORMATION OF PERIMSS}

At the end of the pilot, the project management group used the service evaluation data to inform redesign of the service to reduce reported problems and maximise benefits. The aims were to:

- Redesign the patient pathway for NHS 111 referred patients using lean thinking transformation to demonstrate efficiency and quality of the redesigned service. This revised version of PERMSS would then be proposed to the local CCG Forum for recommissioning in the region.

- Develop a pathway template that would be transferable and allow reproducibility in other healthcare localities.

The lean concept emphasises a systemic, holistic view of process improvement to avoid improvement at subprocesses that shift problems to adjacent subprocesses. Instruments of lean thinking have been applied in hospitals to reduce waste in resources, waiting times and improve productivity. ${ }^{13}{ }^{14}$ The NHS Institute for Innovation and Improvement proposes a range of benefits using the approach of process mapping of a patient journey as shown in box $1 .^{15}$

Hydes et al identified that employment of lean thinking transformation can improve clinical processes to positively influence patients' evaluation of their healthcare experience. Other benefits related to economic benefits to healthcare organisations, such as reduced staffing requirements; increased performance, for example, patient flow and reduced administration costs; improved engagement from staff with more efficient and appropriate use of their time and skill mix. ${ }^{13}$

This study aimed to demonstrate the contribution of community pharmacy $\mathrm{OOH}$ to NHS 111 callers requiring repeat medication supplies via the evaluation the Community PERMSS. The activities underpinned by the concept of lean thinking were undertaken at the end of

\section{Box 1 Benefits of process mapping}

- A starting point for an improvement project specific for your own place of work.

- Creating a culture of ownership, responsibility and accountability for your team.

- Illustrates a patient pathway or process, understanding it from a patient's perspective.

- An aid to plan changes more effectively.

- Collecting ideas, often from staff who understand the system but who rarely contribute to change.

- An interactive event that engages staff.

- An end product (a process map) that is easy to understand and highly visual. 
the pilot period to review and redesign the service with the aim to maximise clinical efficacy and efficiency by eliminating ineffective and unnecessary activity.

\section{METHODS}

\section{Service activity}

Service activity, with patient identifiable information removed, was automatically sent electronically as an Excel spreadsheet via email from PharmOutcomes to the independent evaluator $(\mathrm{HN})$ at the end of the evaluative period. However, patient age and postcode were included in this data set. Extracted data from this data sheet related to:

- Volume and times of day and week of calls to NHS 111 regarding missing medication that were referred to community pharmacy;

- Outcome of that referral by the community pharmacy; accepted, completed, rejected or remain referred;

- The reasons, where provided, for rejected referrals.

PharmOutcomes also collected data on supplies made in community pharmacy as a consequence of completed referrals. These data related to reasons for supply; evidence provided to support supply; medication supplied categorised according to British National Formulary (BNF) chapters; ${ }^{16}$ identification of high-risk medications according to the Patient Safety First Campaign $2008^{17}$ (specifically opiates, insulin, anticoagulants, antipsychotics, Non-steroidal anti-inflammatories (NSAIDs) and diuretics) and the number of additional services and/or pharmaceutical advice provided were recorded.

The North East Ambulance Service that manages the NHS 111 call line provided average call handling times of the 4 months preceding the service (AugustDecember 2014) and the average call handling times in the months where the service was being provided (December 2014-March 2015).

Additionally, NHS North England Commissioning Support Unit provided the average 'did not attend' (DNA) rate of callers to NHS 111 provided with GP $\mathrm{OOH}$ appointments within all participating CCGs during 2014. This figure was used as a comparator to the DNA rate of referred patients to community pharmacy.

\section{Cost comparison of PERMSS to default $\mathbf{0 O H}$ services}

A cost comparison was carried out; however, as health benefits were not included, a comparative evaluation of costs and benefits, for example, cost-effectiveness or cost-benefit analysis, was not performed. The costs of the community pharmacy provisions of emergency supplies were compared with the costs that could have been incurred if the patient had accessed a GP OOH service as had been the default NHS 111 recommendation prior to the service pilot. The GP OOH service was a block contract with no individual cost per consultation. So an estimated cost per individual consultation was calculated by dividing the cost of the block contract by the activity within the region provided by the North of
England Commissioning Support Unit. Calls to NHS 111 cost $£ 8$ per call $^{3}$ and therefore present an additional cost. The costs were calculated based on the evaluative period and also projected annual costs.

\section{Community pharmacist feedback}

The project team designed an electronic questionnaire and circulated it within the local HealthWatch group and the LPN to test for face validity and to provide any comments and approval. The semi-structured questionnaire asked community pharmacists to provide feedback on their understanding and support of the service. Specifically, pharmacists were asked if requests for emergency supply of medicines should be managed by community pharmacists and how well this service aligned to their current role and responsibilities. Pharmacists were asked on the perceived appropriateness of referral from NHS 111; the appropriateness of PharmOutcomes as the platform for this referral and whether the service could be accommodated within the current community pharmacy daily activity. Pharmacists were also asked how this service contributed to workload, impact on consultation time and their satisfaction with the reimbursement process. Finally, pharmacists were asked how supportive they were to providing such a service and if any service improvements were required.

This electronic survey was circulated via PharmOutcomes between 5 January and 7 April 2015. An email message from the Local Pharmacy Committees requesting pharmacists complete the survey was sent on 5 January.

The anonymised community pharmacist feedback was sent electronically as an Excel spreadsheet to the independent evaluator $(\mathrm{HN})$ via email from PharmOutcomes at the end of the evaluation period.

Discussion within the project team and on consultation of the NHS Health Research Authority guidance ${ }^{18}$ identified the study components to be either audit or service evaluation and therefore ethical approval was not required.

\section{Lean thinking transformation of PERMSS \\ Preparation and planning}

The project management team decided that a Kaizen workshop, a multidisciplinary meeting of representative stakeholders, was an appropriate technique for carrying out the lean thinking transformation of the service redesign. The design of the 2-day event was guided by the NHS Modernisation Agency guide to Process mapping, analysis and redesign. ${ }^{15}$ The event took place on 23-24 June 2015, 2 months after the end of the PERMSS pilot. The venue was a neutral off-site environment to prevent participants being distracted and coming in and out of the workshop activities. A list of the stakeholders who attended is included in online supplementary file 1. An evaluative report containing service activity, patient feedback, community pharmacist feedback and NHS 111 call handler feedback was circulated to all participants a week before the event. 
Data collection, mapping the information, analysing the data and problem solving and redesigning the patient journey

During the 2-day Kaizen workshop, the value-stream mapping (process mapping exercise) of the current state of the PERMSS was produced by all stakeholders. This process charted the patient journey from NHS 111 referral to a patient's exit from the service having received or not received a supply of their repeat medications. This mapped out journey was also analysed during the workshop to identify problems such as non-added value, waits or bottlenecks as recommended by Trebble et $a .^{19}$ On the basis of this exercise, the team of stakeholders identified priorities in streamlining the pathway. This was followed by the team redesigning the patient journey as a future state map to increase activities that added value and elimination of those that were waste.

\section{RESULTS}

\section{Service activity}

Over the evaluative period, 1468 patients accessed NHS 111 for requests for emergency supplies of their repeat medication and were referred onto a community pharmacy. The service was provided to NHS 111 referred patients $\mathrm{OOH}$ by pharmacists at $114(52 \%)$ community pharmacies. The largest number of referrals occurred within the first week of April (1st-7th). Table 1 shows the number of patients accessing this service over the evaluative period, the age of patients requiring emergency repeat medication supplies and reasons for the requests.

Of these referrals, $64.8 \%(\mathrm{n}=951)$ were completed, of which $92.4 \% \quad(\mathrm{n}=879)$ patients were entitled to exemption or prepayment. The majority of these referred patients $(58.5 \%, \mathrm{n}=556)$ used an empty pack of previously dispensed medication as evidence of repeat supply. A further $20.9 \% \quad(n=199)$ presented a prescription request form, $4.5 \% \quad(n=43)$ of patients directed the pharmacist to the pharmacy held patient medication record and $2.4 \% \quad(n=23)$ provided a GP letter. The remaining $13.7 \% \quad(n=130)$ patients used other forms of evidence, for example, a previously dispensed Medidose box or a Medication Adherence Record sheet. Patients who received an emergency supply were also provided with advice on effective medicines management $(51.5 \%$, $\mathrm{n}=583)$; medicines reconciliation $(32.9 \%, \mathrm{n}=373)$; prescription request process $(9.5 \%, n=107)$, and $6 \%(n=68)$ of patients were advised on other issues, for example, adherence to medication, home delivery service. The vast majority of patients $(97.3 \%, \mathrm{n}=925)$ were not provided with an additional pharmaceutical service as it was considered unnecessary. However, 5 patients received an MUR $(0.5 \%), 8$ patients signed up for the repeat dispensing service $(0.8 \%)$ and a further 13 patients $(1.4 \%)$ received other services, for example, smoking cessation advice, influenza jab.

The remainder of the referrals were either not actioned (remained referred) $(15.5 \%, \mathrm{n}=228)$; accepted
Table 1 The frequency of referrals made by NHS 111 to community pharmacies, the characteristics of the patient requiring an emergency supply and the reason for their request $(n=1468)$

\begin{tabular}{|c|c|}
\hline $\begin{array}{l}\text { Characteristics of emergency } \\
\text { supply request }\end{array}$ & $\begin{array}{l}\text { Number of } \\
\text { patients (\%) }\end{array}$ \\
\hline \multicolumn{2}{|l|}{ Access by month } \\
\hline December 2014 (15th-31st) & $193(13.1)$ \\
\hline January 2015 (1st-31st) & $274(18.6)$ \\
\hline February 2015 (1st-28th) & $252(17.1)$ \\
\hline March 2015 (1st-31st) & 268 (18.3) \\
\hline April 2015 (1st-7th) & $481(32.7)$ \\
\hline \multicolumn{2}{|l|}{ Access by day } \\
\hline Sunday & 223 (15.2) \\
\hline Monday & $106(7.2)$ \\
\hline Tuesday & $43(2.9)$ \\
\hline Wednesday & $42(2.8)$ \\
\hline Thursday & 77 (5.2) \\
\hline Friday & $306(20.8)$ \\
\hline Saturday & $671(45.7)$ \\
\hline \multicolumn{2}{|l|}{ Age of patient (years) } \\
\hline$<13$ & $120(8.1)$ \\
\hline $13-19$ & $37(2.5)$ \\
\hline $20-29$ & $179(12.1)$ \\
\hline 30-39 & $140(9.5)$ \\
\hline $40-49$ & $142(9.6)$ \\
\hline $50-59$ & 201 (13.6) \\
\hline $60-69$ & $192(13.0)$ \\
\hline$\geq 70$ & 457 (31.0) \\
\hline \multicolumn{2}{|l|}{ Reason for emergency supply request } \\
\hline Ran out of medicines & $1065(72.7)$ \\
\hline GPs closed & $187(12.8)$ \\
\hline Lost medication & $58(3.9)$ \\
\hline Prescription not ready at the GP surgery & $23(1.5)$ \\
\hline Acute presentation & $4(0.2)$ \\
\hline Other & $128(8.7)$ \\
\hline
\end{tabular}

but not completed $(5.8 \%, \mathrm{n}=85)$ or rejected $(13.9 \%$, $\mathrm{n}=204)$. Table 2 shows the reasons for rejections. No stock being available was the most common reported explanation for rejecting a referral $(28.9 \%, n=59)$. In $66.1 \%(n=39)$ of cases where no stock was available, no further action was recorded by the pharmacist. However, in some instances, patients were referred back to NHS $111(13.6 \%, \mathrm{n}=8)$, another pharmacy $(13.6 \%, \mathrm{n}=8)$ or to the hospital $(1.7 \%, \mathrm{n}=1)$. Three of the medications $(5.1 \%)$ were not in stock because they were a special formulation that required specific manufacturing and had to be ordered in advance of supply (usually 5 working days).

Of the 951 NHS 111 referred patients who had 'completed' referrals, 2297 medicines were supplied, an average of 2.4 medicines per patient, with the range in number of medicines supplied from 1 to 9 . Table 3 shows the $\mathrm{BNF}^{16}$ classification of these medicines and the frequency of high-risk medications in accordance with the Patient Safety First campaign. ${ }^{17}$ 
Table 2 The reasons provided by community pharmacists for rejecting a NHS 111 referral

\section{Reasons for rejections $(n=204,14 \%)$}

Medication not in stock $59(28.9)$

Patient did not attend

Error in referral information entered by call $28(13.7)$

handler

Clinically inappropriate to supply*

Patient received supply elsewhere

No evidence provided by the patient

Duplicate referral by NHS 111

procedure $†$

No reason specified

$10(4.9)$

*For example, an acute medication (eg, antibiotic) or controlled drug is required by the patient. This service only allows for the supply of repeat medications and does not allow the supply of controlled drugs apart from the exceptions described above.

†The community pharmacist does not check for any notification of a referral on PharmOutcomes before undertaking the consultation with the patient and providing a medication as per the standard emergency supply regulations. Therefore no entry onto PharmOutcomes was made for remuneration.

The North East Ambulance Service provided data to demonstrate that the average call handling time between August and December 2014 was $6 \mathrm{~min} 31 \mathrm{~s}$ (range, $6 \mathrm{~min} 12 \mathrm{~s}$ to $6 \mathrm{~min} 40 \mathrm{~s}$ ). Within the evaluative period, the average call handling time increased to $10 \mathrm{~min} 24 \mathrm{~s}$ (range, $9 \mathrm{~min} 46 \mathrm{~s}$ to $11 \mathrm{~min} 6 \mathrm{~s}$ ). This was difference of 4 min $12 \mathrm{~s}$, a $64 \%$ increase in call duration.

The average DNA rate of callers to NHS 111 provided with GP $\mathrm{OOH}$ appointments within all participating CGGs during 2014 was $5.56 \%$. Data were provided by NHS North England Commissioning Support Unit.

\section{Cost comparison}

Each patient received an average of 2.4 medications, and therefore the average PERMSS cost was £12.80. For the 951 patients receiving a supply via PERMSS, the cost in reimbursement for the community pharmacist for the consultation was estimated to be $£ 12172.80$. The estimated cost of GP OOH via NHS 111 at $£ 96$ (GP OOH)+ $£ 8$ (NHS 111 call) was $£ 98904$, eight times the cost for supplies made via PERMSS.

\section{Community pharmacist feedback}

Of the 316 community pharmacists who were accredited to undertake this service, 221 ( $70 \%$ response rate) completed the questionnaire and the responses of which are displayed in table 4.

A few community pharmacists disagreed or strongly disagreed that improvements to the service were required $(19 \%, \mathrm{n}=42)$. However, $44 \%(\mathrm{n}=97)$ identified improvements were required, and $37 \% \quad(n=82)$ were unsure. Problems with the service related to referrals being made when community pharmacies were shut $(n=32)$, or during normal GP opening times when
Table 3 The medicines supplied through PERMSS to NHS 111 referred patients as British National Formulary $68^{16}$ classification and high risk drug as classified by the Patient Safety First campaign $2008^{17}$

\begin{tabular}{lr}
\hline Classification of medicine & $\begin{array}{c}\text { Number (\%) } \\
\text { (n=2297) }\end{array}$ \\
\hline BNF classification & $741(32.3)$ \\
Central nervous system & $618(26.9)$ \\
Cardiovascular & $269(11.7)$ \\
Endocrine & $182(7.9)$ \\
Gastrointestinal & $140(6.1)$ \\
Respiratory & $101(4.4)$ \\
Nutrition and blood & $73(3.2)$ \\
Infections & $56(2.4)$ \\
Obstetrics, gynaecology and urinary & $47(2.0)$ \\
Musculoskeletal & $29(1.3)$ \\
Skin & $21(0.9)$ \\
Eye & $15(0.7)$ \\
Malignancies & $5(0.2)$ \\
Ear, nose and oropharynx & \\
High-risk drug category (n=412, 17.9\%) & $106(4.6)$ \\
Anticoagulants & $85(3.7)$ \\
Opiates & $81(3.5)$ \\
Diuretics & $63(2.7)$ \\
Insulin & $61(2.7)$ \\
Antipsychotics & $16(0.7)$ \\
Non-steroidal anti-inflammatories & \\
\hline BNF, British National Formulary; PERMSS, Pharmacy for \\
Emergency Repeat Medication Supply Service. \\
\end{tabular}

patients could access a prescription to cover a medication supply $(\mathrm{n}=27)$, or rejections being made because of lack of stock $(n=34)$. Some pharmacists $(n=14)$ asked for call handlers to have more information and training about medications that can and cannot be issued as an emergency supply through this service, for example, acute medications, medications that have a high risk of abuse (eg, hypnotics) and controlled drugs. It was also identified that more accurate information of pharmacy opening times should be held by NHS $111 \quad(n=13)$. Thirty suggestions related to the addition of a notification in the form of an email or a text message to inform the pharmacist that a referral had been made by NHS 111 via PharmOutcomes.

Community pharmacists $(47 \%, \mathrm{n}=104)$ also identified that further PharmOutcomes training was required to ensure that resident and locum pharmacists would know how to use the system and check for referrals. Training about the current emergency supply regulations $(30 \%$, $\mathrm{n}=66)$ and increasing pharmacist capacity $(16 \%, \mathrm{n}=35)$ were also suggested as facilitators for operating this service.

\section{Lean thinking transformation of PERMSS}

Current state PERMSS patient pathway

There were 23 individual steps of the current patient pathway identified from the value stream map produced from the Kaizen workshop (shown in online 
Table 4 The responses of community pharmacists to the questionnaire items

\begin{tabular}{|c|c|c|c|c|c|}
\hline \multirow[b]{2}{*}{ Survey item } & \multicolumn{5}{|l|}{ n (\%) } \\
\hline & $\begin{array}{l}\text { Strongly } \\
\text { agree }\end{array}$ & Agree & Undecided & Disagree & $\begin{array}{l}\text { Strongly } \\
\text { disagree }\end{array}$ \\
\hline I am clear on the service remit and objectives & $121(54.8)$ & 69 (31.2) & $30(13.6)$ & $1(0.5)$ & 0 \\
\hline $\begin{array}{l}\text { I think this service is aligned to my current competencies, } \\
\text { role and responsibilities }\end{array}$ & $119(53.8)$ & $67(30.3)$ & $34(15.4)$ & 0 & $1(0.5)$ \\
\hline $\begin{array}{l}\text { I think it is appropriate to refer these patients to pharmacy } \\
\text { out of hours }\end{array}$ & $126(57.0)$ & 58 (26.2) & $34(15.4)$ & $2(0.9)$ & $1(0.5)$ \\
\hline PharmOutcomes is an appropriate platform for referrals & $94(42.5)$ & $71(32.1)$ & $39(17.6)$ & $11(5.0)$ & $6(2.7)$ \\
\hline $\begin{array}{l}\text { The service can be comfortably accommodated within the } \\
\text { current activities of the community pharmacy }\end{array}$ & $94(42.5)$ & $74(33.5)$ & $41(18.6)$ & $11(5.0)$ & $1(0.5)$ \\
\hline The process of reimbursement is simple & $80(36.2)$ & $67(30.3)$ & $57(25.8)$ & $13(5.9)$ & $4(1.8)$ \\
\hline I am happy to provide this service in community pharmacy & $114(51.6)$ & $74(33.5)$ & $33(14.9)$ & 0 & 0 \\
\hline This service needs improvements & $33(14.9)$ & $65(29.4)$ & $82(37.1)$ & $28(12.7)$ & $13(5.9)$ \\
\hline
\end{tabular}

supplementary file 2). The patient entered the service by instigating the call to NHS 111, and the successful exit would be the patient receiving a medication supply at a community pharmacy. Of these 23 steps, 12 were identified as adding value, that is, $52.1 \%$ of the patient pathway. Analysis of the pathway revealed fundamental inefficiencies inherent to the pathway design, resulting in unnecessary waiting times (2 contributing steps); duplication of activities ( 4 steps) and a non-added value bottleneck. This contributed to the high proportion of low-value steps, which were likely to have led to the reported increase in NHS 111 call handling times.

\section{Patient pathway redesign}

The current state process map was re-engineered to a lean thinking system with a redesigned patient pathway through PERMSS (see online supplementary file 2) to a future state. This resulted in the reduction of constituent steps by $30.4 \%$ (6 steps); a subsequent increase in steps adding value to $68.9 \%(11 / 16$ steps) and reduction in waste (3 duplication steps and the bottleneck removed). The process redesign reflected a streamlined employment of the referral platform to improve the appropriate use of time and skills of the non-clinical call handlers and to maximise the contribution of the community pharmacist in the pathway.

\section{DISCUSSION}

PERMSS is a service that responds to a national recommendation for community pharmacy to contribute to reducing workload pressure on the wider NHS. ${ }^{20} 21$ It also meets the recent endorsement by Morecroft et $a l^{22}$ for an NHS-funded emergency supply service. This evaluation demonstrates that current systems, that is, NHS 111, PharmOutcomes and the current community pharmacy regulations for emergency supply medication, can be adapted and employed to operationalise a service to direct NHS 111 callers to community pharmacy. We also show that PERMSS when conservatively compared with the unit cost of the alternative GP OOH service offers a more economical option to the NHS for the management of these patients $\mathrm{OOH}$. This service not only offers patients a solution for their primary request, that is, an emergency supply of medication, but also retains contact with a healthcare professional for any additional or opportunistic pharmaceutical advice or service provision. Morecroft et $a t^{23}$ also described emergency supply requests to community pharmacists as an opportunity to engage with patients over issues relating to adherence, medication management and medication taking via MUR. Further studies also highlight how contact with community pharmacists provides a time for opportunistic advice around health promotion and medication-related issues, ${ }^{24} 25$ which are a by-product of a service that directs patients to this healthcare professional. Our previous study, evaluating PERMSS from the entry point of self-presenting patients at community pharmacy $\mathrm{OOH}$ with a request for an emergency supply of repeat medication, detailed results similar to those reported here in relation to demographics of patients requiring such a service; timings of highest level of activity; types of medications requested and levels of high-risk medications. $^{26}$ A recent mixed methods evaluation of patients, pharmacists and GPs perspectives of emergency supply requests to community pharmacy ${ }^{23}$ also mirrored the results of the current study, as many requests are from the elderly and those with long-term conditions, but also all age groups are represented among service users and a diversity in medications requested. Our study on the self-presenting patients accessing PERMSS also demonstrated that community pharmacists expressed support for such a service to be provided within community pharmacy since it aligned with their roles and could be accommodated within their daily activities. $^{26}$ This service meets both aspects of the business versus professional role dichotomy of community pharmacy, where positive patient outcomes are balanced with strong business performance. ${ }^{27}$ As such the support for its implementation and delivery could be predicted 
to be high. Further qualitative data collection from community pharmacists that probed aspects of the Normalisation Process Model $^{28}$ would provide more information on the barriers and facilitators to the service implementation and delivery. A consideration of the 'completion' rate presented here is that it may be an underestimation, as those 'accepted', or 'remain referred' may actually have been completed but not entered onto PharmOutcomes as an additional entry to normal practice. This limitation is in common with our previous study ${ }^{26}$ where a record of emergency supply may not have been recorded in PharmOutcomes but instead within the patient medication record and/or in the private prescription record, as is common practice. Patients self-presenting for PERMSS expressed high satisfaction and claimed that this process for obtaining an emergency supply was more easily accessible compared to other OOH services. ${ }^{26}$ This would suggest that NHS 111 referred patients would have had a similar experience, but specific feedback from this patient group would be required to investigate the impact of the NHS 111 referral component additional in this patient journey and is a limitation of this study. However, the DNA rate of NHS 111 referred patients presenting at community pharmacy was $3.86 \%$ (57 of the 1468 patients referred), which is lower than the reported GP OOH DNA rates across the North East for the year 2014 $(5.56 \%)$, which suggests potential patient acceptability of this service. In our previous study, ${ }^{26}$ we also discussed the potential to raise public awareness of the emergency supply service. The current unease within the community pharmacy profession ${ }^{22}$ may be abated by the introduction of Summary Care Records, allowing pharmacists to monitor for abuse of accessing this service instead of attending GP appointments. ${ }^{26}$

This study does not demonstrate what proportion of calls to NHS 111 for this disposition were referred to community pharmacy and therefore redirected away from urgent and emergency care. These data are crucial to understand the value of this service in the wider NHS. Also it is important to understand the motivation and trust of call advisors in directing callers to community pharmacy. Turnball et al found that success of NHS 111 depends on understanding and trusting relationships between the different organisations providing different aspects of the NHS 111 service and managing the often risk averse CDSS. ${ }^{29}$

Morecroft $e t a l^{22} 23$ provided qualitative and quantitative data on the status quo of emergency supply requests through community pharmacy and recommended the initiation of an NHS-funded national emergency supply service via community pharmacy. This summative service evaluation provides the descriptive quantitative and operational data of such a piloted service within the North East of England. This study does not, however, explore the perceived added value to the patients in terms of adherence to their medication regimen or potential clinical outcomes; benefits suggested by
Morecroft et al..$^{23}$ The collection of these humanistic and clinical outcomes, as framed by the economic, clinical and humanistic outcomes (ECHO) model, ${ }^{30}$ within future work alongside the evaluation of the revised PERMSS would further augment the gravitas and significance of this service. Further limitations to this study are that it does not offer an in-depth understanding of the service implementation, causal mechanisms to explore service activity and the context of the delivery and findings. By undertaking a complex evaluation, including a process evaluation, as framed by the Medical Research Council guidance, ${ }^{31}$ the holistic nature of service delivery and outcomes would be investigated.

The lean thinking transformation demonstrated a standardised systematic approach to deconstructing the constituent elements of a service, understanding and justifying their significance in the process from the perspectives of all stakeholders. This allowed development of an optimised procedure that could theoretically improve effectiveness and efficiency. Limitations in the reporting of the service improvement workshop include the lack of evaluation that would inform the critical reader of the context and operation and allow reproducibility. Despite this, this study follows the NHS recommendations to undertake this exercise to improve and innovate healthcare service provision. To empirically substantiate this process, the service activity and stakeholder feedback subsequent to the implementation and operation of the newly redesigned future state version of PERMSS should be evaluated and compared to the results of this study. This evaluative work is planned following initiation and operation of the newly designed and commissioned PERMSS.

\section{CONCLUSION}

Systems and processes within the operation of NHS 111 can be adapted to direct callers for emergency supply requests of repeat medication to open community pharmacies $\mathrm{OOH}$. Current information technology platforms used by community pharmacy, for example, PharmOutcomes, can be used to transmit such referrals. Community pharmacists express support and acceptability of this process. Patients are directed away from GP OOH to a contracted NHS healthcare provider for management of their request and provision of supportive advice and services. Lean thinking transformation provided a structured framework to analyse the current service in terms of the patient journey and redesign the pathway for potential efficiency and effectiveness. The revised service pathway and description of the intervention provide a template for national adoption to allow callers to NHS 111 to be referred for requests for emergency supplies of their repeat medication to community pharmacy.

Twitter Follow Hamde Nazar at @NazarHamde

Contributors AY and JS designed and implemented the intervention. JS and AY also managed and recorded the lean thinking transformation exercise 
during the Kaizen workshop. HN designed the service evaluation and community pharmacy survey. $\mathrm{HN}$ extracted the data and is guarantor. $\mathrm{HN}$ and ZN analysed the data. HN, ZN, AY, JS and CW all discussed the results and interpretation. All authors were involved in the drafting the initial text for the report and revising drafts prior to publication, and all approved the submission.

Funding This research received no specific grant from any funding agency in the public, commercial or not-for-profit sectors.

Disclaimer The views expressed are those of the author(s) and not necessarily those of NHS England or Newcastle City Council.

Competing interests JS has support from NHS England for the submitted work and AY has support from Newcastle City Council.

Ethics approval Discussion within the project team and on consultation of the NHS Health Research Authority guidance identified the study components to be either audit or service evaluation and therefore ethical approval was not required.

Provenance and peer review Not commissioned; externally peer reviewed.

Data sharing statement No additional data are available.

Open Access This is an Open Access article distributed in accordance with the Creative Commons Attribution Non Commercial (CC BY-NC 4.0) license, which permits others to distribute, remix, adapt, build upon this work noncommercially, and license their derivative works on different terms, provided the original work is properly cited and the use is non-commercial. See: http:// creativecommons.org/licenses/by-nc/4.0/

\section{REFERENCES}

1. Head of Clinical Governance. Health Committee: written evidence from NHS Direct NHS Trust (ES 31). Parliamentary business. April 2013. http://www.publications.parliament.uk/pa/cm201314/cmselect/ cmhealth/171/171vw25.htm (accessed 10 Sep 2015).

2. NHS England. NHS 111 Quality and Safety Report. 2014. https:// www.england.nhs.uk/wp-content/uploads/2014/07/nhs111-qualsafety-rep.pdf (accessed 7 Sep 2015).

3. Turner J, O'Cathain A, Knowles E, et al. Impact of the urgent care telephone service NHS 111 pilot sites: a controlled before and after study. BMJ Open 2013;3:e003451.

4. BBC News Team. Winter pressure-how helpful is NHS 111? BBC News 16 December 2014. http://www.bbc.co.uk/news/health30507649 (accessed 1 Jul 2015).

5. NHS England. NHS 111 Minimum Data Set 2015. http://www. england.nhs.uk/statistics/category/statistics/nhs-111-statistics/ (accessed 15 Jul 2015).

6. NHS England. Community pharmacy-helping provide better quality and resilient urgent care. 2014. http://www.england.nhs.uk/ wp-content/uploads/2014/11/comm-pharm-better-quality-resilienturgent-care.pdf (accessed $10 \mathrm{Jul}$ 2015).

7. Statutory Instruments. The Human Medicines Regulations 2012. No. 1916. London: The Stationery Office, 2012.

8. NHS England. Quick guide: extending the role of community pharmacy in urgent care. 2015. https://www.england.nhs.uk/commissioning/ wp-content/uploads/sites/12/2015/11/quick-guid-comm-pharm-urgentcare.pdf (accessed 4 Dec 2015).

9. NHS England. Five Year Forward View. 2014. https://www.england. nhs.uk/wp-content/uploads/2014/10/5yfv-web.pdf (accessed 13 Oct 2015).

10. Royal Pharmaceutical Society. Shaping pharmacy for the future: improving urgent and emergency care through better use of pharmacists. 2014. http://www.rpharms.com/policy-pdfs/ urgent-and-emergency-care.pdf (accessed 13 Oct 2015).

11. Pharmaceutical Services Negotiating Committee (PSNC) PharmOutcomes. http://psnc.org.uk/services-commissioning/ pharmoutcomes/ (accessed 3 Jul 2015)

12. NHS Cumbria, Northumberland and Tyne and Wear and Durham, Darlington and Tees Area. Service level agreement for an NHS Community Pharmacy Emergency Repeat Medication Supply Service (PERMSS): pilot scheme. 2014. http://psnc.org.uk/ sunderland-lpc/wp-content/uploads/sites/89/2014/12/PERMSS-SLAFinal.pdf (accessed 1 Jun 2015).

13. Hydes T, Hansi N, Trebble TM. Lean thinking transformation of the unsedated upper gastrointestinal endoscopy pathway improves efficiency and is associated with high levels of patient satisfaction. BMJ Qual Saf 2012;21:63-9.

14. Trebble T, Hydes T. Redesigning services around patients and their doctors: the continuing relevance of lean thinking transformation. Clin Med 2011;11:308-10.

15. NHS Modernisation Agency. Process mapping, analysis and redesign. London: Department of Health, 2005:1-40.

16. Joint Formulary Committee. British National Formulary. 68 ed. London: BMJ Group and Pharmaceutical Press; 2015.

17. Patient Safety First. The 'How to Guide' for reducing harm from high risk medicines. 2008. http://www.patientsafetyfirst.nhs.uk/ashx/Asset ashx?path=/How-to-guides-2008-09-19/Medicines\%201.1_ 17Sept08.pdf (accessed $1 \mathrm{Jul} 2015$ ).

18. NHS Health Research Authority. Research community. http://www. hra.nhs.uk/research-community/ (accessed 9 Oct 2015).

19. Trebble T, Hansi N, Hydes T, et al. Process mapping the patient journey: an introduction. BMJ 2010;341:394-7.

20. Wilkinson E. Call for national scheme for pharmacies to supply emergency medicines. Pharm J 2015;295:7874-5.

21. NHS England. Community pharmacy - helping with winter pressures. 2013. http://www.england.nhs.uk/wp-content/uploads/2013/12/winterpressures_community-pharmacy-services.pdf (accessed 10 Jul 2015).

22. Morecroft $\mathrm{C}$, Stokes L, Mackridge A, et al. An evaluation of the role of community pharmacists in optimising safe and appropriate medicines use in response to patient requests for emergency supplies: Emergency Supply of Prescription-only Medicines (ESoPoMs). Liverpool John Moores University, 2014.

23. Morecroft CW, Mackridge AJ, Stokes EC, et al. Emergency supply of prescription-only medicines to patients by community pharmacists: a mixed methods evaluation incorporating patient, pharmacist and GP perspectives. BMJ Open 2015;5:e006934.

24. Anderson $C$. Health promotion in community pharmacy: the UK situation. Patient Educ Couns 2000;39:285-91.

25. Moore S, Cairns C, Harding G, et al. Health promotion in community pharmacy. Int J Pharm Prac 1996;2:95-100.

26. Nazar H, Nazar Z, Simpson J, et al. A summative service and stakeholder evaluation of an NHS-funded community Pharmacy Emergency Repeat Medication Supply Service (PERMSS). BMJ Open 2016;6:e009736.

27. Jacobs $S$, Ashcroft $D$, Hassell K. Culture in community pharmacy organisations: what can we glean from the literature? J Health Organ Manag 2011;25:420-54.

28. May C. A rational model for assessing and evaluating complex interventions in health care. BMC Health Serv Res 2006;6:86-97.

29. Turnball J, Pope C, Rowsell A, et al. The work, workforce, technology and organisational implications of the '111' single point of access telephone number for urgent (non-emergency) care: a mixed methods case study. Health Serv Deliv Res 2014;2 (3):1-140.

30. Kozma CM, Reeder CE, Schulz RM. Economic, clinical and humanistic outcomes: a planning model for pharmacoeconomic research. Clin Ther 1993;15:1121-32.

31. Moore G, Audrey S, Barker M, et al. Process evaluation of complex interventions: Medical Research Council guidance. BMJ 2015;350: h1258 